\title{
Are the kids all right? A look at flourishing among school-age children and youth in Minnesota
}

\author{
BY MARVIN SO, MPH, AND ANNA LYNN, MPP
}

Flourishing is a state characterized by positive social and behavioral functioning in children, which can be influenced by family, health care, and community factors. The National Survey of Children's Health (NSCH) provides an opportunity to describe characteristics of the children who are-and are not yet-flourishing at the state level. Using the 2016-2017 NSCH to calculate prevalence estimates and odds ratios (ORs), this study examined parents' perspectives on Minnesota children aged 6-17 in households, and explored select child, family, and health care correlates. The findings indicate that $41.4 \%$ of children in the state met flourishing criteria. Unadjusted ORs demonstrated differences in flourishing by child, family, and health care characteristics; after accounting for relevant covariates, parent-child connectedness, family resilience during difficult times, medical home status, and encountering adverse childhood experiences remained significantly associated with flourishing. Through highlighting factors predictive of parent-perceived flourishing, this study outlines potential insights for intervention that could accelerate child and adolescent well-being in Minnesota.

\section{Background}

Minnesota consistently ranks as one of the best places in the country for child and family health. ${ }^{1,2}$ In contrast to these accolades, children's health and educational disparities across race, socioeconomic status, and geography in Minnesota are well-known, ${ }^{3-6}$ and have prompted efforts by both providers ${ }^{7,8}$ and the state government ${ }^{9,10}$ to address their root causes. Although previous examinations of children's health across the state have told us much about negative outcomes, we have relatively less information about indicators of successful development. ${ }^{11}$

Flourishing, or thriving, is a concept that embodies the World Health Organization edict that health comprises more than simply the absence of physical or mental disorders. ${ }^{12}$ Flourishing has gained traction in recent years, given its associations with aspects of child well-being (e.g., BMI, ${ }^{13}$ school engagement ${ }^{14}$ ), with calls to better define, measure, and even incentivize flourishing within health care systems. ${ }^{12,15,16}$ Ultimately, flourishing can be described as positive mental health, and research suggests that self-regulation, interest in learning, communication, and positive relationships are key attributes for young people. ${ }^{17-19}$ Possessing such assets reflect overall vitality and can translate to physiologic, immunologic, and social function-even when confronted with health risks like stress or infectious disease. ${ }^{17,18}$

Since 2017, the Minnesota Department of Health $(\mathrm{MDH})$ has convened a statewide learning community to develop values and strategies that promote "public mental well-being." ${ }^{20}$ This workgroup, along with other efforts, ${ }^{21,22}$ illustrates burgeoning interest in understanding and enhancing positive dimensions of health, rather than solely avoiding morbidity and mortality. Although health care systems have historically focused on identifying and treating health conditions, promoting flourishing may represent a complementary path for optimizing child wellness beyond diagnoses. Taking stock of flourishing in Minnesota could therefore help us better understand communities' needs, and elucidate opportunities for allocating services or improving existing supports.

\section{Methods}

This study used the National Survey of Children's Health (NSCH), a household survey designed to generalize to the population of non-institutionalized children in each state and nationally. ${ }^{23}$ Parents completed an electronic or paper survey asking questions related to the health, development, and risk and protective factors of a randomly selected child in the household. Although previous studies have characterized flourishing nationwide, ${ }^{24,25}$ there have been few efforts to do so in Minnesota.

The three flourishing-related items in the NSCH are based on developmentally relevant milestones and experiences for school-age children; they ask parents to report how well a given statement described their child: (1) "shows interest and curiosity in learning new things," (2) "works to finish tasks he or she starts," and (3) "stays calm and in control when faced with a challenge." These items align with con- 
structs we define as "curiosity about learning," "self-regulation," and "resilience," respectively. ${ }^{26}$ Consistent with prior work, ${ }^{25}$ the three items were summed to create an overall child flourishing index (range: 0-3). Children whose parents reported that every statement was "definitely true" were classified as flourishing (i.e., scored $3 / 3$ for the overall index). These questions were developed through an extensive process engaging experts, parents, and the literature ${ }^{25}$ providing support to their construct validity. Other relevant measures included individual items (e.g., parentchild connectedness) and composite indicators of adverse childhood experiences (ACEs), family resilience during difficult times, household socioeconomic status, receipt of public assistance, and receipt of care within a medical home model-all constructed in accordance with previous studies. ${ }^{25,27}$ Missing data were replaced using imputation methods, described elsewhere. $^{28}$

To maximize the stability of estimates, we combined data from the 2016 and 2017 surveys (variables and response options used in this analysis did not change between years). ${ }^{26}$ Effectively, the analytic sample consisted of all Minnesota children ages 6-17 in residences with valid responses for all three flourishing-related items $(n=1,214)$. First, to contextualize childhood flourishing in this state, we calculated unadjusted prevalence estimates and 95\% confidence intervals (CIs) of childhood flourishing for Minnesota, states in U.S. Health Resources and Services Administration Region V overall (including Illinois, Indiana, Michigan, Minnesota, Ohio, and Wisconsin), and nationwide. Nested $t$-tests were used to investigate if Minnesota was significantly different compared to regional and national estimates. Second, we used logistic regression to calculate unadjusted odds ratios (ORs) and 95\% CIs of flourishing by various child, family, and health care characteristics; these analyses were then replicated, adjusting for sex, race/ethnicity, age, parental education, and special health care need status. We chose variables documented to covary with flourishing, ${ }^{24,25}$ cor- roborated using stepwise forward selection procedures. Analyses were conducted in Stata V16.1 (College Station, TX), using weights to account for the complex sample design and non-response; effectively, findings reflect the sociodemographic diversity of children throughout the state.

\section{Results}

The survey responses in the analytic sample were representative of 835,658 children in Minnesota households. Overall, $41.4 \%$ of children ages 6-17 were reported by parents to be flourishing (Figure 1). This prevalence was higher than both the national and regional average, although the difference was not statistically significant. When examining individual items, there were also comparable rates of selfregulation, resilience, and curiosity about learning in Minnesota relative to regional and nationwide prevalence, with one exception: the prevalence of curiosity about learning was significantly higher in Minnesota relative to the average prevalence in the region ( $86.8 \%$ vs. $82.4 \%$; $p=0.03$ ).

Within Minnesota, there were differences in flourishing by child, family, and health care characteristics based on crude estimates (Table 1). Specifically, lower prevalence of flourishing was observed among children who were in the younger age category (6-11 years), were boys, experienced ACEs, or were non-White. At the family level, children living in households with lower household income, that received public assistance, that primarily spoke a non-English language, had parents who were born outside the United States, had low parent-child connectedness, or did not possess family resilience, evidenced lower prevalence of childhood flourishing. With respect to health care, children who lacked a medical home had lower levels of flourishing, as did those on public insurance or a public-private combination (compared to those solely on private insurance). Children who were uninsured demonstrated a higher flourishing prevalence.

Flourishing significantly varied by child race/ethnicity, age category, ACEs category, family resilience, parent-child con- nectedness, receipt of public assistance, insurance type, and medical home status. After controlling for key covariates, four factors remained significantly predictive. Children in families that demonstrated low parent-child connectedness or lacked qualities of family resilience in the face of problems were less likely to be flourishing compared to their counterparts with these family characteristics (adjusted OR: 0.25, 95\% CI: 0.16-0.39 and adjusted OR: 0.29, 95\% CI: 0.19-0.46, respectively). Children lacking a medical home were also less likely to be flourishing compared to children receiving services aligned with the medical home model (adjusted OR: 0.59, 95\% CI: 0.41-0.84), as were children who experienced two or more ACEs relative to children who experienced no ACEs (adjusted OR: 0.22, 95\% CI: 0.13-0.37).

\section{Discussion}

We found that two in five of Minnesota's school-age children were described by parents to be flourishing. Although this rate is comparable to nearby states and the overall country, it nonetheless underscores that the majority of children and youth do not meet flourishing criteria. There were significant differences in flourishing by certain child, family, and health care characteristics that stakeholders invested in children should contemplate. Of note: adjusted models showed that several aspects traditionally viewed as indicators of childhood disadvantage, such as household socioeconomic status, were not significantly associated with flourishing after controlling for factors that might explain putative differences. As we work to rectify the concerning disparities documented here (e.g., by race/ethnicity), this finding suggests that flourishing may be possible regardless of children's circumstances. Several factors can be considered as potential elements of healthful developmental contexts, discussed below. $^{25,29}$

Flourishing provides a more comprehensive portrait of pediatric health, conveying how children function, to complement previous studies focused on states of impairment such as depression. ${ }^{4,5}$ These results can further be related to informa- 


\section{Child, family, and health care characteristics associated with flourishing among children ages 6-17 in Minnesota, 2016-2017}

\begin{tabular}{|c|c|c|c|}
\hline CHARACTERISTIC & $\begin{array}{l}\text { Flourishing }^{\mathrm{a}} \\
\%(95 \% \text { Cl) }\end{array}$ & $\begin{array}{c}\text { Unadjusted OR } \\
\%(95 \% \text { CI) }\end{array}$ & $\begin{array}{l}\text { Adjusted OR } \\
\%(95 \% \text { Cl) }\end{array}$ \\
\hline OVERALL & $41.4(37.2-45.7)$ & --- & --- \\
\hline \multicolumn{4}{|l|}{ CHILD } \\
\hline RACE/ETHNICITY: White, non-Hispanic & $45.5(40.8-50.2)$ & (Reference) & (Reference) \\
\hline RACE/ETHNICITY: Black, non-Hispanic & $19.5(4.3-34.6)^{\mathrm{d}}$ & $0.29(0.10-0.78)^{*}$ & $0.30(0.06-1.12)$ \\
\hline RACE/ETHNICITY: Hispanic & $32.8(18.9-46.7)^{\mathrm{d}}$ & $0.59(0.30-1.13)$ & $0.65(0.33-1.28)$ \\
\hline RACE/ETHNICITY: Other, non-Hispanic ${ }^{c}$ & $39.2(26.4-51.9)^{\mathrm{d}}$ & $0.77(0.44-1.36)$ & $0.78(0.44-1.36)$ \\
\hline AGE: 6-11 years old & $36.4(30.5-42.2)$ & (Reference) & (Reference) \\
\hline AGE: $12-17$ years old & $46.1(40.0-52.2)$ & $1.50(1.05-2.13)^{*}$ & $1.02(0.53-1.96)$ \\
\hline SEX: Female & $43.4(37.7-49.1)$ & (Reference) & (Reference) \\
\hline SEx: Male & $39.7(33.4-45.9)$ & $0.86(0.60-1.22)$ & $0.83(0.59-1.16)$ \\
\hline ADVERSE CHILDHOOD EXPERIENCES ${ }^{\mathrm{e}}: 0$ ACES & $48.2(42.9-53.5)$ & (Reference) & (Reference) \\
\hline ADVERSE CHILDHOOD EXPERIENCES ${ }^{\mathrm{e}}: 1$ ACE & $43.9(33.5-54.3)^{\mathrm{d}}$ & $0.84(0.52-1.35)$ & $0.82(0.52-1.30)$ \\
\hline ADVERSE CHILDHOOD EXPERIENCES ${ }^{\mathrm{e}}: 2+$ ACES & $18.0(11.1-25.0)$ & $0.24(0.14-0.40)^{*}$ & $0.22(0.13-0.37)^{*}$ \\
\hline \multicolumn{4}{|l|}{ FAMILY } \\
\hline HOUSEHOLD SOCIOECONOMIC STATUS ${ }^{\mathrm{f}}: 400 \%$ FPL or greater (highest) & $46.6(40.3-52.8)$ & (Reference) & (Reference) \\
\hline HOUSEHOLD SOCIOECONOMIC STATUS ${ }^{\mathrm{f}}: 200-399 \%$ FPL & $41.9(34.0-49.9)$ & $0.83(0.54-1.26)$ & $0.87(0.56-1.34)$ \\
\hline HOUSEHOLD SOCIOECONOMIC STATUS ${ }^{\mathrm{f}}: 100-199 \%$ FPL & $38.7(26.1-51.2)^{\mathrm{d}}$ & $0.72(0.41-1.28)$ & $0.81(0.46-1.42)$ \\
\hline HOUSEHOLD SOCIOECONOMIC STATUS ${ }^{\mathrm{f}}$ :0-99\% FPL (lowest) & $28.6(13.1-44.2)^{\mathrm{d}}$ & $0.46(0.19-1.08)$ & $0.63(0.26-1.51)$ \\
\hline PARENTAL NATIVITY: Parent(s) born in the U.S. & $42.7(38.1-47.4)$ & (Reference) & (Reference) \\
\hline PARENTAL NATIVITY: Any parent born outside U.S. & $38.8(27.8-49.9)^{\mathrm{d}}$ & $0.85(0.52-1.41)$ & $1.32(0.74-2.37)$ \\
\hline PRIMARY LANGUAGE AT HOME: English & $42.9(38.6-47.3)$ & (Reference) & (Reference) \\
\hline PRIMARY LANGUAGE AT HOME: Non-English & $27.5(9.8-45.2)$ & $0.51(0.20-1.25)$ & $0.79(0.29-2.13)$ \\
\hline FAMILY RESILIENCE DURING DIFFICULT TIMEs ${ }^{\mathrm{g}}$ : Demonstrates family resilience & $46.7(41.6-51.7)$ & (Reference) & (Reference) \\
\hline FAMILY RESILIENCE DURING DIFFICULT TIMES ${ }^{g}$ : Does not demonstrate family resilience & $21.9(15.3-28.6)$ & $0.32(0.21-0.50)^{*}$ & $0.29(0.19-0.46)^{*}$ \\
\hline PUBLICASSISTANCE $\mathrm{h}^{\mathrm{h}}$ Receives public assistance & $30.1(21.0-39.2)$ & (Reference) & (Reference) \\
\hline PUBLICASSISTANCE ${ }^{\mathrm{h}}$ :Does not receive public assistance & $45.0(40.3-49.7)$ & $1.90(1.19-3.04)^{*}$ & $1.60(0.99-2.57)$ \\
\hline PARENT-CHILD CONNECTEDNESS ${ }^{\mathrm{i}}$ :High parent-child connectednesS & $50.3(45.0-55.6)$ & (Reference) & (Reference) \\
\hline PARENT-CHILD CONNECTEDNESS ${ }^{\mathrm{i}}$ :Low parent-child connectednesS & $21.3(15.5-27.0)$ & $0.27(0.18-0.40)^{*}$ & $0.25(0.16-0.39)^{*}$ \\
\hline \multicolumn{4}{|l|}{ HEALTH CARE } \\
\hline INSURANCE STATUS: Private only & $44.9(40.3-49.6)$ & (Reference) & (Reference) \\
\hline INSURANCE STATUS: Public only & $27.8(17.9-37.8)$ & $0.47(0.28-0.80)^{*}$ & $0.63(0.35-1.11)$ \\
\hline INSURANCE STATUS: Private and public & $39.3(20.0-58.6)^{\mathrm{d}}$ & $0.79(0.35-1.82)$ & $0.81(0.35-1.89)$ \\
\hline INSURANCE STATUS: Uninsured & $62.1(36.7-87.4)^{\mathrm{d}}$ & $2.01(0.67-5.60)$ & $2.11(0.77-5.75)$ \\
\hline MEDICAL HOME': Care meets medical home criteria & $47.3(41.5-53.1)$ & (Reference) & (Reference) \\
\hline MEDICAL HOME: Care does not meet medical home criteria & $34.6(28.4-40.8)$ & $0.59(0.41-0.84)^{*}$ & $0.59(0.41-0.84)^{*}$ \\
\hline
\end{tabular}

NOTES. OR: Odds Ratio. 95\% Cl: 95\% Confidence Interval. FPL: Federal Poverty Level.

a Based on children for whom each flourishing-related statement was "definitely true".25,26

b Adjusted for sex, race/ethnicity, age, parental education, and special health care need status.26

CIncludes children reported to be Asian American Indian, Alaska Native, Native Hawaiian/Pacific Islander, multi-racial, or other

d Estimate has a 95\% CI width exceeding $20 \%$, suggesting greater uncertainty about the true prevalence. This estimate should be interpreted with caution.

e Adverse childhood experiences was determined based on parent report about whether their child ever experienced any of the following: hard to get by on family's income; parent or guardian divorced or separated; parent or guardian died; parent or guardian served time in jail; saw or heard parents or adults slap, hit, kick punch one another in the home; was a victim of violence or witnessed violence in neighborhood; lived with anyone who was mentally ill, suicidal, or severely depressed; lived with anyone who had a problem with alcohol or drugs; and treated or judged unfairly due to race/ ethnicity.

$\mathbf{f}_{\text {Household socioeconomic status was }}$ classified based on federal poverty leve categories, determined based on family income, size, and composition using U.S. Census Bureau thresholds.

g Family resilience during difficult times was determined based on parent report about whether their family talks together about what to do, works together to solve problems, knows they have strengths to draw on, and stays hopeful even during difficult times when faced with a problem.

$\mathbf{h}_{\text {Receipt of public assistance was }}$ determined based on parent report of receipt of any of the four benefits in the last 12 months: cash assistance; Women, Infants, and Children; Supplemental Nutrition Assistance Program (i.e., food stamps); or free/reduced cost meals at school.

i Parent-child connectedness was determined based on parent report of how well they can share ideas or talk about things with the child that really matter. Children were classified as having high parent-child connectedness if the parent responded "very well"to this question; all othe children were classified as having low parent-child connectedness.

jeceiving care that meets medical home criteria was determined based on parent report of child having a personal doctor or nurse, usual source of care, and family-centered care. Additionally, any children needing referrals or care coordination must also meet those criteria.

* Statistically significant difference from reference group 
tion from the Minnesota Student Survey, which captures additional components of mental well-being such as empowerment and social competence. ${ }^{30}$ Although study design differences preclude direct comparisons, the two surveys could be examined jointly in state efforts to stimulate positive development.

This study has clear limitations. First, the analysis relied on cross-sectional data, limiting the ability to infer causality or direction of effects. Second, surveys were completed by parent self-report; although caregivers are likely the optimal reporter for these concepts, ${ }^{18}$ this may have introduced social desirability, recall, or reporter bias. Third, although early efforts have been made to validate the child flourishing index, it is a population-level indicator and its application within clinical settings requires further inspection. Fourth, certain prevalence estimates possessed wide confidence intervals, which could be due to small sample sizes or extensive variability within subgroups; they need to be viewed critically in concert with other state data.

Finally, and meriting major consideration, our definition of flourishing is best understood as reflective of children's context and relationships at multiple socioecological levels. It should not be interpreted as an immutable characteristic, but rather as a holistic marker of child wellbeing, pliable to change through medical, social, and community supports. Despite these issues, this article provides an initial profile of childhood flourishing in Minnesota. Additional research is needed to test mechanisms, probe for possible clinical and policy levers, and layer patient and provider perspectives onto these findings. For example, there could be other characteristics or skills that families would describe as demonstrating flourishing, and these characteristics might look different across cultures or communities. It would also be crucial to learn more about flourishing among populations not well addressed with this dataset (e.g., Native American children).

Implications for practice. There is some difficulty in positioning study find-

\section{FIGURE 1 \\ Prevalence estimates of flourishing items and overall index among children ages 6-17 in Minnesota, regionally, ${ }^{\mathrm{a}}$ and nationwide, 2016-2017}
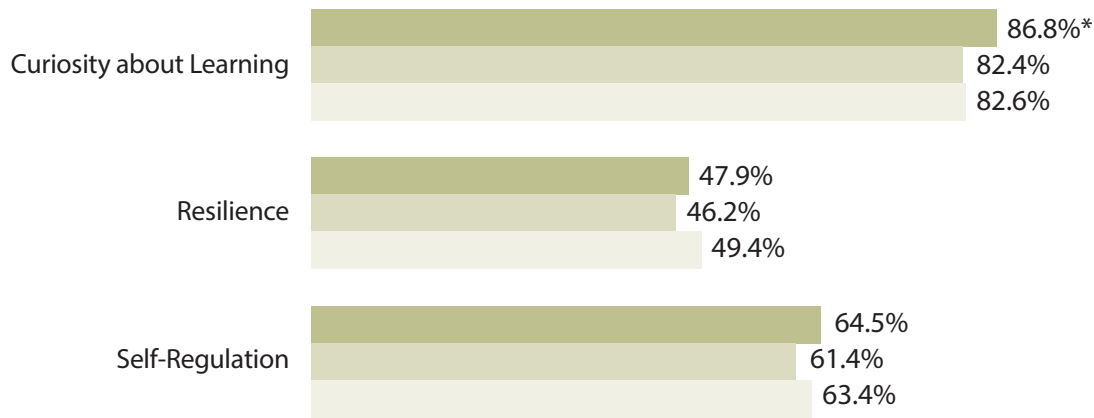

$61.4 \%$

$63.4 \%$



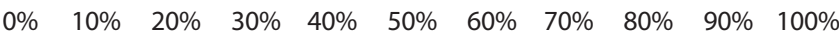
Percentage of children aged 6-17

Minnesota Region Nationwide

$a_{\text {Regional estimate is based on the average prevalence among the six states in U.S Health Resources and Service }}$ Administration Region V, which includes: Illinois, Indiana, Michigan, Minnesota, Ohio, and Wisconsin. * Statistically significant difference from regional average.

ings within clinical practice, as validated screening instruments and decision-making approaches based on flourishing are still nascent. ${ }^{16}$ However, compelling arguments have been made that "the science of thriving" has already reached sufficient clarity and momentum to warrant redesigning health care systems to promote positive indicators of health. ${ }^{15,31}$ Placing greater focus on components of existing tools (e.g., prosocial sub-scale of the Strengths and Difficulties Questionnaire) may be a place to start. Regardless of one's practice setting, the medical home, parentchild connectedness, and family resilience findings deserve consideration by clinicians. Providers that structure services to align with medical home principles might observe benefits for flourishing in pediatric patients. The medical home framework proposes that clinically- and cost-effective health care for children and youth is accessible, continuous, comprehensive, coordinated, compassionate, culturally effective, and family-centered. ${ }^{26}$ Similarly, provider actions to assess and support family relationships and coping could also foster flourishing.

As others propose, ${ }^{32}$ primary care providers are well positioned to not only screen for anomalies, but also ask about and support protective factors. These clinicians are trusted professionals accessed by the majority of families-including those of lower socioeconomic standing ${ }^{27}$ -representing a key touchpoint for intervention. Understandably, some providers may feel that high-quality management of childhood illness and physical health is already a considerable task. Promoting flourishing in practice may seem a nebulous proposition, but giving attention to these factors can contribute to a more holistic clinical impression of children and help build skills and routines that actually remain salubrious for families beyond any single visit. ${ }^{32-34}$ While clinicians' ability to overcome entrenched social determinants may have limits, enhancing curiosity about learning, resilience, and self-regulation reflect more proximal targets and can buffer patients from health risks. Such efforts align with contemporary guidance 
for optimal primary care, ${ }^{35}$ and can range from small practice changes to more formal partnerships. For example, to promote curiosity about learning, providers could create "literacy-rich" clinic environments, provide anticipatory guidance about the importance of unstructured play, or connect families to relevant resources (e.g., afterschool programs). Advocating for the structural changes below may also constitute a key task for providers.

Implications for systems. Minnesota is among the nation's leaders in advancing value-based payment reform through Medicaid-setting the stage for a health care system that might meaningfully address, measure, and pay for the social and emotional components of child health. ${ }^{36,37}$ In tandem, there are clear examples of on-the-ground efforts to promote holistic well-being (see the MDH's Minnesota Thrives resource database ${ }^{21}$ ), and research activities are increasingly incorporating indicators of patient and community assets. ${ }^{11,30,38}$ To build on this foundation, health, educational, social service, and other systems could facilitate or incentivize the delivery of evidence-based interventions known to promote dimensions contained within the flourishing measure (e.g., self-regulation), such as social-emotional learning, ${ }^{34,39}$ mindfulness, ${ }^{40}$ and positive parenting programs. ${ }^{33,41}$ It will be vital to consider which communities stand to benefit most from improved dissemination of interventions-such as those experiencing socioeconomic disadvantage or behavioral health provider shortages. ${ }^{42}$ Finally, children with a history of two or more ACEs exhibited 78\% lowered odds for flourishing relative to peers with no ACEs, representing the largest effect size among our adjusted models with significant findings. Effectively, prioritization of policies that reduce exposure to ACEs (e.g., parental incarceration) could mitigate health

\section{Changing the negative mindset}

As a pediatrician, I am excited about a measure of positive mental health for pediatric patients as an alternative to the typical metrics regarding the absence of disease. In clinical work, we screen patients and families for negative deviance. If an elevated maternal depression screen, PHQ-9, GAD 7, or failure of achievement on developmental screen is noted, our resultant plan of action is to mitigate further negative impact on a child's mental health and development. We may also screen for ACES, again looking for the potential negative impact of familial or environmental situations on our patients based on odds ratios and population risk. This approach constitutes an inherently negative mindset-a mindset that parents may interpret as a pessimistic message of affliction or problem noted in their child.

Flourishing is an excellent example of a positive metric that can counter-balance parents' perceptions of negativity or their defeatist mindsets. Highlighting what is positive or going well for a child allows a parent to focus on augmenting protective factors that are often in their control, instead of focusing on the elimination of negative factors for which they have less agency. Using a positive metric like flourishing can also provide a beneficial direction for clinicians' action planning. Clinicians could prioritize action plans such as: 1) enhancing parent-child connectedness and child curiosity of learning through programs like Reach Out and Read; 2) building family resiliency through partnering with families to lessen the impacts of $\mathrm{SDOH}$; or 3 ) designating a clinic as a medical home. These are examples of protective, concrete recommendations that can help parents work towards positive outcomes.

The flourishing metric also aligns with that which is paramount to pediatrics: preventive care to optimize lifelong health. The public health aspects of preventative care cannot be solved by the health care sector alone-they require the coordination of multiple sectors of society, and this coordination would benefit greatly from a common language. The flourishing metric offers a standardized framework that all societal sectors could use as a measure of community success for children.

consequences $^{40}$ and simultaneously bolster flourishing.

\section{Conclusion}

Although we remain clear-eyed about the importance of addressing diagnosable pediatric health conditions, these findings cast light onto another facet of the status of children. Providers and systems seeking to improve family outcomes can do more than ensure young people have problems assessed or illnesses managed. We should also imagine what supports and resources they need to function well and thrive. These data suggest that clinical and community actions addressing parent-child connectedness, family resilience, access to comprehensive medical care, and ACEs can move us closer to population-wide flourishing for our children and youth. MM

Marvin So, MPH, is a student at the University of Minnesota Medical School. Anna Lynn, MPP, is Mental Health Promotion Coordinator, Minnesota Department of Health.

\section{Acknowledgment}

We thank Rebecca Wiersma and anonymous reviewers for their excellent suggestions, and the Data Resource Center for Child and Adolescent Health for supplying the NSCH 2016-2017 dataset. A preliminary version of this analysis was shared at the 2019 Minnesota Chapter of the American Academy of Pediatrics Hot Topics in Pediatrics Conference.

\section{REFERE N CE S}

1 Annie E. Casey Foundation. 2020 KIDS COUNT Data Book. Baltimore, MD; 2020.

2 United Health Foundation. America's Health Rankings ${ }^{\oplus}$ Annual Report. Minneapolis, MN; 2019.

3 Snowden AM, Xiong M, Nelson G, Strub B. 2016 Health Equity of Care Report. Minneapolis, MN; 2017.

4 Nitardy CM, Duke NN, Pettingell SL, Borowsky IW. Racial and Ethnic Disparities in Educational Achievement and Aspirations: Findings from a Statewide Survey from 1998 to 2010. Matern Child Health J. 2014;19(1):58-66. doi:10.1007/s10995-014-1495-y

5 Bjur KA, Wi C II, Ryu E, et al. Socioeconomic Status, Race/Ethnicity, and Health Disparities in Children and Adolescents in a Mixed Rural-Urban CommunityOlmsted County, Minnesota. Mayo Clin Proc 2019;94(1):44-53. doi:10.1016/j.mayocp.2018.06.030

6 Children's Defense Fund Minnesota. Minnesota Kids Count 2018: Building Community in a Time of Changing Needs. St. Paul, MN; 2018.

7 Minnesota Chapter of the American Academy of Pediatrics. Poverty \& Disparities. http://www.mnaap.org/ work-groups/poverty-disparities/. Accessed January 15, 2020.

8 Minnesota Medical Association. Health Equity. https:// www.mnmed.org/advocacy/Key-Issues/Health-Equity. Accessed January 30, 2020.

9 Minnesota Department of Health. Advancing Health 
Equity in Minnesota: Report to the Legislature. St. Paul, MN; 2014.

10 Minnesota Department of Health. Eliminating Health Disparities Initiative: Minnesota Department of Health Report to the Minnesota Legislature 2016. St. Paul, MN; 2016.

11 Chase R. Advocating for indicators of community assets and well-being. https://www. mncompass.org/trends/insights/2019-04-02-advocating-for-community-asset-indicators. Published 2019. Accessed January 15, 2020.

12 Vanderweele TJ, McNeely E, Koh HK. Reimagining Health - Flourishing. JAMA. 2019. doi:10.1001/jama.2019.3035

$13 \mathrm{Kim}$ TE, Jang CY. The relationship between children's flourishing and being overweight. J Exerc Rehabil. 2018;14(4):598. doi:10.12965/jer.1836208.104

14 Jones DE, Greenberg M, Crowley M. Early Social-Emotional Functioning and Public Health: The Relationship Between Kindergarten Social Competence and Future Wellness. Am J Public Health. 2015;105(11):2283-2290. doi:10.2105/AJPH.2015.302630

15 Bethell CD, Solloway MR, Guinosso S, et al. Prioritizing Possibilities for Child and Family Health: An Agenda to Address Adverse Childhood Experiences and Foster the Social and Emotional Roots of Well-being in Pediatrics. Acad Ped. 2017;17(7S):S36-S50. doi:10.1016/j. acap.2017.06.002

16 Bethell CD, Kennedy S, Martinez-Vidal E, Simpson L. Payment for Progress: Investing to Catalyze Child and Family Well-Being Using Personalized and Integrated Strategies to Address Social and Emotional Determinants of Health. Washington, D.C.; 2018.

17 Huppert FA. Psychological well-being: Evidence regarding its causes and consequences. Appl Psychol Health Well Being. 2009;1(2):137-64. doi: 10.1111/j.17580854.2009.01008x

18 Moore KA, Bethell CD, Martin MC. Flourishing From the Start: What Is It and How Can It Be Measured? Bethesda, MD: Child Trends; 2017.

19 Witten H, Savahl S, Adams S. Adolescent flourishing: A systematic review. Cogent Psychol. 2019;6(1). doi:10.1080/23311908.2019.1640341

20 Minnesota Department of Health. Mental Well-Being and Resilience Learning Community. https://www.health.state.mn.us/communities/mentalhealth/community. html. Published 2019. Accessed January 15, 2020

21 Minnesota Department of Health. Minnesota Thrives: Building Connections for Mental Well-Being and Resilience. https://www.health.state.mn.us/communities/mentalhealth/ mnthrives.html. Published 2019. Accessed January 15, 2020

$\mathbf{2 2}$ Keyes C. Languishing and flourishing: A community perspective. University of Minnesota Extension Children Youth \& Family Consortium. https://extension.umn.edu/ cyfc-update/cyfc-update-feb-2019. Published 2019. Accessed March 7, 2020.

23 Ghandour RM, Jones JR, Lebrun-Harris LA, et al. The Design and Implementation of the 2016 National Survey of Children's Health. Matern Child Health J. 2018;22(8). doi:10.1007/s10995-018-2526-x

24 Kandasamy V, Hirai AH, Ghandour RM, Kogan MD. Parental Perception of Flourishing in School-Aged Children. J Dev Behav Pediatr. April 2018:1. doi:10.1097/ DBP.0000000000000559

25 Bethell CD, Gombojav N, Whitaker RC. Family resilience and connection promote flourishing among US children, even amid adversity. Health Aff. 2019;38(5):729-737. doi:10.1377/hlthaff.2018.05425

26 Child and Adolescent Health Measurement Initiative (CAHMI). National Survey of Children's Health 2016-2017 Stata Indicator Data Set. www.childhealthdata.org.

$\mathbf{2 7}$ Cree RA, Bitsko RH, Robinson LR, et al. Health Care, Family, and Community Factors Associated with Mental, Behavioral, and Developmental Disorders and Poverty Among Children Aged 2-8 Years — United States, 2016. MMWR Morb Mortal Wkly Rep. 2018;67(50):1377-1383. doi:10.15585/mmwr.mm6750a1

28 U.S. Census Bureau. 2017 National Survey of Children's Health: Imputation Data Guide. Washington, D.C.; 2018.

29 Kwong TY, Hayes DK. Adverse family experiences and flourishing amongst children ages 6-17 years: 2011/12 National Survey of Children's Health. Child Abus Negl. 2017;70:240-246. doi:10.1016/j.chiabu.2017.06.016

30 Minnesota Department of Health. Minnesota Adolescent Mental Well-Being. St. Paul, MN; 2019.

31 Courtwright SE, Flynn Makic MB, Jones J. Emotional wellbeing in youth: A concept analysis. Nurs Forum. 2019;55(2):106-117. doi:10.1111/nuf.12404

32 Taliaferro LA, Borowsky IW. Beyond prevention: promoting healthy youth development in primary care. Am J Public Health. 2012;102 Suppl 3:S317-21. doi:10.2105/ AJPH.2011.300559

33 Teti DM, Cole PM, Cabrera N, Goodman SH, McLoyd VC. Supporting Parents: How Six Decades of Parenting Research Can Inform Policy and Best Practice. Soc Policy Rep 2017;30(5):1-34. doi:10.1002/j.2379-3988.2017.tb00090.x

34 Pandey A, Hale D, Das S, Goddings A-L, Blakemore S-J, Viner RM. Effectiveness of Universal Self-regulation-Based Interventions in Children and Adolescents. JAMA Pediatr. 2018;172(6):566. doi:10.1001/jamapediatrics.2018.0232

35 Hagan J, Shaw J, Duncan P, eds. Recommendations for Preventive Pediatric Health Care. In: Bright Futures: Guidelines for Health Supervision of Infants, Children, and Adolescents. 4th ed. Elk Grove Village, IL: American Academy of Pediatrics; 2017.
36. Bailit Health. Value-Based Payment Models for Medicaid Child Health Services. Needham, MA; 2016

37 Dybdal K, Blewett L, Sonier J, Spencer D. Paying for Value in Medicaid: A Synthesis of Advanced Payment Models in Four States. Washington, D.C.: Medicaid and CHIP Payment and Access Commission; 2014

38 Keyes CLM. Mental health in adolescence: Is America's youth flourishing? Am J Orthopsychiatry. 2006;76(3):395-402. doi:10.1037/0002-9432.76.3.395

39 Graziano PA, Hart K. Beyond behavior modification: Benefits of social-emotional/selfregulation training for preschoolers with behavior problems. J Sch Psychol. 2016;58:91 111. doi:10.1016/j.jsp.2016.07.004

40 Bethell C, Gombojav N, Solloway M, Wissow L. Adverse Childhood Experiences, Resilience and Mindfulness-Based Approaches: Common Denominator Issues for Children with Emotional, Mental, or Behavioral Problems. Child Adolesc Psychiatr Clin N Am. 2016;25(2):139-156. doi:10.1016/j.chc.2015.12.001

41 Morris AS, Robinson LR, Hays-Grudo J, Claussen AH, Hartwig SA, Treat AE. Targeting parenting in early childhood: A public health approach to improve outcomes for children living in poverty. Child Dev. 2017;88(2):388-397. doi:10.1111/cdev.12743

42 Centers for Disease Control and Prevention. Behavioral health services in Minnesota. https://www.cdc.gov/childrensmentalhealth/stateprofiles-providers/minnesota/index. html. Published 2019. Accessed March 7, 2020

\section{EMPLOYMENT OPPORTUNITIES}

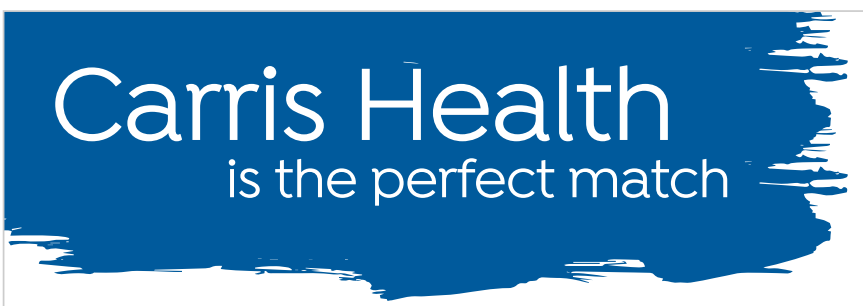

Carris Health is a multi-specialty health network located in west central and southwest Minnesota and is the perfect match for healthcare providers who are looking for an exceptional practice opportunity and a high quality of life.

\section{CURRENT OPPORTUNITIES AVAILABLE FOR BE/ BC PHYSICIANS IN THE FOLLOWING SPECIALTIES:}

$\begin{array}{lll}\text { - Anesthesiology } & \cdot \text { Hospitalist } & \cdot \text { Orthopedic Surgery } \\ \text { - Dermatology } & \cdot \text { Internal Medicine } & \cdot \text { Psychiatry } \\ \text { - ENT } & \cdot \text { Nephrology } & \cdot \text { Psychology } \\ \text { - Family Medicine } & \cdot \text { Neurology } & \cdot \text { Pulmonary/ } \\ \text { - Gastroenterology } & \cdot \text { OB/GYN } & \text { Critical Care } \\ \text { - General Surgery } & \cdot \text { Oncology } & \cdot \text { Rheumatology } \\ & & \cdot \text { Urology }\end{array}$

Loan repayment assistance available.

FOR MORE INFORMATION:

Shana Zahrbock,

Physician Recruitment

Shana.Zahrbock@carrishealth.com

(320) 231-6353 | carrishealth.com

CarrisHealth

Centracare 